\title{
Why Visual and Vocal Interview Cues Can Affect Interviewers' Judgments and Predict Job Performance
}

\author{
Timothy DeGroot \\ Catholic University of America
}

\author{
Stephan J. Motowidlo \\ University of Florida
}

\begin{abstract}
Using videotaped interviews with 60 managers in utility companies, the authors found that a composite of vocal interview cues (pitch, pitch variability, speech rate, pauses, and amplitude variability) correlated with supervisory ratings of job performance $(r=.18, p<.05)$. Using videotaped interviews with 110 managers in a news-publishing company, the authors found that the same composite of vocal cues correlated with performance ratings $(r=.20, p<.05)$ and with interviewers' judgments $(r=.20, p<.05)$ and that a composite of visual cues (physical attractiveness, smiling, gaze, hand movement, and body orientation) correlated with performance ratings ( $r=.14, p<.07$ ) and with interviewers' judgments $(r=.21, p<.05)$. Results of tests of mediation effects indicate that personal reactions such as liking, trust, and attributed credibility toward interviewees explain relationships (a) between job performance and vocal cues and (b) between interviewers' judgments and both visual and vocal cues.
\end{abstract}

Empirical research has firmly established that nonverbal visual cues displayed by interviewees affect interviewers' judgments about their suitability for employment (e.g., Gifford, $\mathrm{Ng}$, \& Wilkinson, 1985; Imada \& Hakel, 1977; McGovern \& Tinsley, 1978; Raza \& Carpenter, 1987; Young \& Beier, 1977). Nonverbal vocal cues such as pitch (e.g., Edwards, 1982), speech rate (e.g., Brown, 1980), and pauses (e.g., Scherer, 1978) that have been linked to the favorability of impressions formed by listeners might also affect interviewers' judgments but have not yet been studied as much as visual cues in the context of employment interviews. Recent research suggests that visual cues in the interview can also be valid predictors of job performance (Burnett, 1993; Motowidlo \& Burnett, 1995).

If visual and vocal cues affect interviewers' judgments and predict job performance, we need to understand the mechanisms through which they have these effects. Research reported in this article explores the idea that the intervening mechanism linking nonverbal interview cues with interview judgments and job performance involves

Timothy DeGroot, Department of Business and Economics, Catholic University of America; Stephan J. Motowidlo, Department of Management, University of Florida.

Correspondence concerning this article should be addressed to Timothy DeGroot, who is now at the Department of Human Resources and Management, Michael G. DeGroote School of Business, McMaster University, 1280 Main Street West, Hamilton, Ontario, Canada L8S 4M4. Electronic mail may be sent to degroott@mcmaster.ca. personal reactions that interviewers and coworkers form about applicants and incumbents based on the nonverbal cues they display.

Many jobs, but especially managerial jobs, demand successful personal interaction for effective performance. To be effective, managers must be able to gain others' cooperation, communicate their ideas persuasively and compellingly, and successfully influence others to accept their ideas. Managers should be more successful interpersonally when their subordinates, peers, and superiors like and trust them, believe they are competent, acknowledge their dominance, allow themselves to be persuaded by them, are inclined to comply with their influence attempts, and are willing to help them. Thus, if subordinates, peers, and superiors form personal reactions such as these (i.e., trust, liking, attributed credibility, etc.) toward the manager, he or she is more likely to be effective in the managerial role.

\section{Nonverbal Visual Cues in the Employment Interview}

Several studies have shown that visual cues displayed by interviewees, such as physical attractiveness, eye contact, body orientation, smiling, and hand gestures, affect the favorability of interviewers' judgments about their suitability for employment (e.g., Cash \& Kilcullen, 1985; Hollandsworth, Kazelskis, Stevens, \& Dressel, 1979; Imada \& Hakel, 1977; Kinicki \& Lockwood, 1985; McGovern \& Tinsley, 1978; Parsons \& Liden, 1984; Raza \& Carpenter, 1987; Wexley, Fugita, \& Malone, 1975; Young \& Beier, 1977). Burnett (1993) and Motowidlo and Burnett (1995) 
have shown that visual cues in the interview can also be correlated with supervisory ratings of job performance. Burnett (1993) reported that supervisory ratings of job performance correlated with a measure of physical attractiveness based on appearance in the interview $(r=.21, p<.05)$ and with the amount of time interviewees gazed at the interviewer $(r=.20, p=.06$ ). She also reported that a composite score that included measures of physical attractiveness, amount of gaze, amount of smiling, amount of hand movement, posture, body orientation, dress characteristics, and vocal attractiveness correlated with interview judgments $(r=.33, p<.01)$ and with supervisory performance ratings $(r=.21, p<.05)$.

On the basis of this research, we expect that five specific visual cues are especially likely to create a favorable personal impression in the selection interview and on the job. We expect that interviewees who are physically attractive, smile more, gaze more in the interviewer's direction, use expressive hand movements more, and lean toward instead of away from the interviewer are most likely to create a favorable impression.

\section{Nonverbal Vocal Cues in the Employment Interview}

Although visual interview cues have been extensively studied, paralinguistic or vocal cues have received relatively little attention in the context of employment interviews. There is a rich theoretical and empirical literature on vocal cues, but very little of it deals directly with issues related to work or organizational behavior. This literature generally assumes that vocal characteristics are unique to the speaker (Greene \& Mathieson, 1989) and that although some especially accomplished speakers can vary some of their vocal characteristics when they choose to (Pearce \& Brommel, 1972), most people have little control over many of their vocal characteristics and cannot easily suppress or disguise them (Greene \& Mathieson, 1989). Thus, this literature treats vocal cues as stable personal characteristics that may indicate underlying personality traits and emotional states (Nighswonger \& Martin, 1981).

Several vocal cues have been found to be related to variables that reflect personal impressions in ways that suggest they might affect the favorability of interviewers' judgments. One such vocal cue is fundamental frequency, the overall characteristic pitch of a voice (Aronovitch, 1976; Sharf \& Lehman, 1984). Even though higher pitch is associated with favorable impressions for women in some jobs, we suspect that management samples place a premium on leadership, which is probably stereotypically associated with a deeper (lower pitched) and stronger voice. Consequently, the overall linear relationship between vocal pitch and impression favorability in management samples is more likely to be negative than positive for both men and women.
Another vocal characteristic that might be associated with interviewers' judgments about potential for managerial effectiveness is the range or variability of voice pitch. Speakers who vary their voice pitch considerably seem to come across as more dynamic, extraverted, benevolent, and competent (Brown, Strong, \& Rencher, 1973; Greene \& Mathieson, 1989; Scherer, 1979).

Several studies found that faster rates of speech are also associated with perceptions of competence and extraversion (Buller, LePoire, Aune, \& Eloy, 1992; Mehrabian \& Williams, 1969; Pearce \& Brommel, 1972; Brown et al., 1973).

The amount of voice breaks or pauses is another variable potentially related to interviewers' judgments about managerial effectiveness. Scherer (1978) found an inverse relationship between length of pause and favorable ratings. Thus, we suspect that the overall linear relationship between amount of voice breaks or pauses and interviewers' judgments about potential for managerial effectiveness is negative.

A fifth vocal cue that might be related to interviewers' judgments of management potential is amplitude variability, which represents short-term instability in the loudness of a voice (Greene \& Mathieson, 1989). Amplitude variability has been associated with perceptions of hoarseness, an undesirable vocal quality (Baken, 1987). For this reason, we expect that amplitude variability will be negatively related to the favorability of interviewers' judgments about an applicant's management potential.

\section{Research Purpose}

Research reported in this article tested relationships between nonverbal visual and vocal cues displayed by interviewees and (a) personal reactions, such as liking, trust, and attributed credibility, that interviewers might form toward interviewees and that coworkers might form toward managerial job incumbents; (b) interviewers' judgments about interviewees' suitability for employment; and (c) interviewees' job performance. We tested whether the reason interviewees' visual and vocal cues affect interviewers' judgments is that interviewers form personal reactions such as trust, liking, and attributed credibility toward interviewees, in part on the basis of their visual and vocal cues, and whether they let their personal reactions affect their judgments about interviewees' suitability for employment.

Because many nonverbal cues are thought to be stable and consistent aspects of social presentation that people express similarly across different interpersonal situations, we assume that people display the same or similar nonverbal cues in the interview as job applicants that they display on the job as incumbents. Consequently, personal impressions and reactions formed by interviewers toward applicants on the basis of nonverbal cues displayed in the interview should be similar to personal impressions and 
reactions formed by coworkers toward applicants who have been hired and now presumably display the same nonverbal cues on the job. Thus, research reported here tests the possibility that personal reactions such as trust, liking, and attributed credibility, formed on the basis of interview cues, also mediate relationships between visual and vocal cues and managerial job performance.

\section{Study 1}

Because vocal cues have not yet been studied much in the context of employment interviews, we conducted a preliminary study to test the feasibility of scoring recorded interviews for vocal cues and to confirm our expectations regarding the directional effects of specific vocal cues on job performance. For this purpose, we used a set of recorded interviews that were collected by Burnett (1993). Details of how she developed structured interview questions to assess dimensions of management effectiveness and administered them to managers in utility companies are reported elsewhere (Burnett, 1993; Motowidlo \& Burnett, 1995). Therefore, only a brief summary of these procedures is presented here.

\section{Method}

Four structured interview questions assessed management potential in the areas of leadership, teamwork, drive, and planning and organizing. They are similar to questions that constitute the patterned behavior description interview (Janz, 1982) and the structured behavioral interview (Motowidlo et al., 1992) in that they ask about interviewees' actual behavior in past situations resembling situations that might happen on the job.

Managers in four utility companies were asked to pretend that they were applying for their present positions and answer interview questions accordingly. They were recorded on videotape. We used the same 60 videotaped interviews in this study that were used by Burnett (1993) and Motowidlo et al. (1996). Of these, 37 were also used in the study reported by Motowidlo and Burnett (1995). However, we only used the interviews to compare their job performance ratings to measures of the interviewees' vocal cues, data that have not been previously reported.

The sample of 60 interviewees includes 15 managers from one company, 18 from a second company, 12 from a third company, and 15 from a fourth company. Twenty-eight managers are women and 32 are men. By race, they include 43 Whites, 10 Blacks, 2 Asians, 2 Hispanics, and 3 others from racial groups different from those just mentioned or not reported. Thirty-three managers had up to 1 year of tenure, 16 had 1 to 2 years of tenure, and 11 had more than 2 years of tenure.

Supervisors of the participating managers rated their job performance on the same dimensions that were used to guide development of the interview questions-leadership, teamwork, drive, and planning and organizing. They also rated them on a fifth dimension of overall performance. We summed the five performance ratings to form a total performance score for each interviewee.
Computer-based methods of voice and speech analysis have been demonstrated to be useful tools for measuring vocal cues objectively (Scherer, London, \& Wolf, 1973). To use these methods in our study, we isolated two random samples of interviewees' speech, each about $10 \mathrm{~s}$ long, and fed them into a computerized speech analyzer. This process allowed us to obtain scores for five vocal cues displayed by interviewees.

Pitch. Pitch is the average fundamental frequency over an entire speech sample. It measures how high or low a voice is. The habitual average pitch level is about $128 \mathrm{~Hz}$ for men and about 225 $\mathrm{Hz}$ for women (Boone, 1977). To remove this sex difference, we subtracted a constant of 97 from pitch levels obtained for female interviewees. We measured pitch separately in each of the two speech samples. The correlation between them was .85 , which, when adjusted by the Spearman-Brown prophecy formula, yielded a reliability estimate of .92 for the two measurements combined.

Pitch variability. This is the standard deviation of the fundamental frequency within each voice sample. Each of the two speech samples provided a separate measure of pitch variability. The correlation between them was .55 , for an estimated reliability of .71 for the two combined.

Speech rate. Most studies have used counts of syllables per second to measure speech rate. In our study, however, interviewees did not follow a standard script and this made it very difficult to count syllables per second. Therefore, we measured length of the pitch period-how long speakers held a constant level of pitch-as a surrogate. To check whether length of pitch period is a reasonable substitute for rate of syllable utterance, we computed both measures for a small sample of interviewees. The correlation between syllable counts and length of pitch period was .88 . Speech rate measured as length of pitch period in the two speech samples was correlated $(r=.85, p<.01)$, yielding a reliability estimate of .92 for their combination.

Pauses. This variable represents amount of nonvoice time in the speech sample. It takes into account not just the number of pauses, but their duration as well. The correlation between pause scores in the two samples of speech was .27 , for a reliability estimate of .47 for the two measurements combined.

Amplitude variability. Finally, amplitude variability assesses variability of the short-term peak-to-peak amplitude within the voice sample. This variable shows how much the speaker involuntarily varies his or her level of volume. Amplitude variation scores in the two speech samples we collected were correlated ( $r=$ $.57, p<.01)$, for an estimated reliability of .73 for the two measurements combined.

As mentioned, we expect that the favorability of personal impressions and reactions will be positively related to speech rate and pitch variability and negatively related to pitch, pauses, and amplitude variability in samples of managers. Therefore, we computed an overall vocal cue index by summing standard scores for speech rate and pitch variability, and subtracting standardized scores for pitch, pauses, and amplitude variability.

\section{Results}

As shown in Table 1, correlations between separate vocal cue scores and job performance are quite small. All are in the expected direction, but none reaches statistical significance. The correlation between overall vocal cue index and 
Table 1

Correlations Between Vocal Cues and Performance Ratings in Study 1

\begin{tabular}{|c|c|c|c|c|c|c|c|}
\hline Variable & 1 & 2 & 3 & 4 & 5 & 6 & 7 \\
\hline 1. Pitch & - & & & & & & \\
\hline 2. Pauses & .29 & - & & & & & \\
\hline 3. Amplitude variability & .39 & .39 & - & & & & \\
\hline 4. Pitch variability & .10 & .16 & .24 & - & & & \\
\hline 5. Speech rate & -.08 & -.66 & -.53 & -.04 & - & & \\
\hline 6. Vocal cue index & -.57 & -.75 & -.71 & .16 & .76 & - & \\
\hline 7. Performance rating & -.21 & -.07 & -.04 & .17 & .04 & .18 & - \\
\hline$M$ & 105.05 & 2.06 & 13.96 & 15.05 & 7.71 & 0.02 & 26.73 \\
\hline$S D$ & 28.56 & 2.49 & 5.53 & 8.37 & 1.76 & 2.94 & 4.27 \\
\hline
\end{tabular}

Note. $N=60$. Correlations greater than .25 are significant at $p<.05$ (two-tailed).

performance ratings is not statistically significant $(r=.18)$; nevertheless, these results show that it is feasible to measure vocal cues through computerized methods applied to videotaped interviews. The consistent direction of correlations with performance offers some encouragement to test for these relationships again, but in a study that affords more statistical power than was available here. Thus, Study 2 tested these relationships in a larger sample of interviewees, with one-tailed tests supported by directional results of Study 1, and with a larger number of voice samples per speaker for better reliability, to boost statistical power.

\section{Study 2}

Study 2 tested the main questions guiding this research effort. Using a different set of videotaped interviews from that used in Study 1, it tested relationships between visual and vocal interview cues and (a) personal reactions based on interview cues, (b) interviewers' judgments based on all information available in the videotaped interviews, and (c) ratings of job performance.

\section{Method}

Interview development and administration. We developed a structured behavioral interview to identify people with management potential in a large news-publishing organization. The interview included nine questions designed to assess management potential in leadership, concern for others, effective problem solving, professional integrity, customer service, and promoting diversity. As part of an effort to validate the interview against criterion ratings of job performance, two doctoral students interviewed incumbent managers. They asked the managers to answer interview questions as if they were applying for their current positions and recorded the interviews on videotape. Each manager was interviewed by one student.

This study uses videotaped interviews with 110 managers in the news-publishing company. This group of managers consists of 56 women and 54 men, all with less than 3 years of experience in their current managerial positions ( $M=2.03$ years). By race, the sample includes 81 Whites, 17 Blacks, 9 Hispanics, and 3 Asians. Their average age is approximately 37.3 years.

Interview ratings. We mailed several videotaped interviews to each of 26 persons who were employed by the news organization in positions similar to those that might be held by people who would actually conduct these interviews operationally. They had no prior acquaintance with the interviewees they were asked to rate. They were instructed to play each videotape, follow along on a written copy of the interview guide, take notes if they wished in the spaces provided in the guide, and rate the interviewee on leadership, concern for others, effective problem solving, professional integrity, customer service, promoting diversity, and oral communication. Each dimension was rated with a 7-point, behaviorally anchored scale. We summed raters' evaluations across these dimensions to yield a single score for the interview judgment. Dimension definitions can be found in DeGroot (1997).

Performance ratings. We collected performance ratings for managers who were interviewed from their immediate supervisors and others in their departments who were familiar with their job performance. Although we collected multiple ratings for each manager, the ratings were not independent because different raters often discussed a manager's performance before making their evaluations. The average number of supervisors that rated each manager was 2.15. Ratings were made on the same dimensions (using the same 7-point, behaviorally anchored scales) on which interview ratings were made, plus an additional dimension for overall performance. We computed a mean score across all raters who evaluated each manager and across all the performance dimensions.

Visual cues. We prepared the videotaped interviews for visual analysis by dividing them into quintiles according to the total performance score and then selecting 22 sets of five interviews, with each set including one interview from each performance quintile. We randomly sampled a total of $2 \mathrm{~min}$ of video play from the beginning, middle, and end of each interview and prepared another videotape showing a 2-min sample of each of the five interviews in a set, with each sample separated by a 1-min blank divider. Thus, we had 22 videotapes, each showing a 2-min sample of five interviews that represented all levels of job performance.

Undergraduate research participants judged visual cues on the basis of these videotaped samples. Five students watched each 
videotaped sample, without sound, and judged interviewees on physical attractiveness, amount of smiling, amount of gaze in the direction of the interviewer, amount of hand movement, and extent to which the interviewee leaned toward instead of away from the interviewer. Thus, 110 students participated as judges of visual cues. Each student rated five interviews and each interview was rated by five students.

We combined ratings across five raters for each visual cue. Interrater reliability estimates for five raters combined, on the basis of the intraclass correlation, are .77 for physical attractiveness, .87 for amount of smiling, .80 for amount of gaze in the direction of the interviewer, .90 for amount of hand movement, and .90 for body orientation toward the interviewer. We also computed an overall visual cue index by combining the five visual cue scores. Its interrater reliability estimate for five raters combined, again on the basis of the intraclass correlation adjusted according to the Spearman-Brown formula, is .93 .

Vocal cues. We prepared an audiotape recording of four samples of interviewees' speech from different parts of each interview. Each sample was approximately $10 \mathrm{~s}$ in duration. We fed these speech samples into a computerized voice analyzer in the same way as in Study 1 and obtained measures of the same five vocal cues as in Study 1: pitch, pitch variability, speech rate, pauses, and amplitude variability. Again, we subtracted a constant of 97 from pitch scores for women to adjust for sex differences. Internal consistency reliability estimates for four measures combined are .93 for pitch, .62 for pitch variability, .85 for speech rate, .89 for pauses, and .82 for amplitude variability. We also computed an overall vocal cue index by standardizing each cue score, summing speech rate and pitch variability, and subtracting pauses, amplitude variability, and pitch. The internal consistency reliability estimate for the overall vocal cue index combined over four measurement samples is .82 .

Personal reactions. We prepared a questionnaire to measure seven types of personal reactions toward the managers who were interviewed, including how much people might like the manager, trust the manager, believe the manager is competent, accept the manager's dominance, allow themselves to be persuaded by the manager, are inclined to comply with the manager's influence attempts, and are willing to help the manager. Each personal reaction was tapped by two items using anchored 7-point scales (available from the first author upon request).
For personal reactions based on visual cues, a different sample of 110 undergraduates each watched one of the 22 videotapes described above, without sound, and rated their personal reactions toward each of the managers they saw. That is, they rated the extent to which they thought they would personally like the manager, trust the manager, believe the manager is competent, and so on. For personal reactions based on vocal cues, another sample of 110 undergraduates each listened (without a picture) to one of the 22 videotapes and rated their personal reactions toward each of the managers they heard. We summed across the 14 items for each rater and combined total scores for all raters who saw or heard the same manager. The inter-rater reliability estimate for five raters combined, on the basis of intraclass correlations adjusted by the Spearman-Brown formula, is .93 for the personal reaction score based on visual cues and .96 for the personal reaction score based on vocal cues.

\section{Results}

The analytic logic described by Baron and Kenny (1986) stipulates three requirements for establishing mediation effects. The first is that regressing the mediator on the independent variable must yield a significant effect for the independent variable on the mediator. The second is that regressing the dependent variable on the independent variable must yield a significant effect for the independent variable on the dependent variable. And the third is that regressing the dependent variable on both the mediator and the independent variable must yield a significant effect for the mediator on the dependent variable. If all three requirements are met, the independent variable has a weaker effect on the dependent variable in the third regression equation than in the second, according to Baron and Kenny. In our case, the independent variables are the visual and vocal cue indexes, the mediator variables are visual and vocal personal reaction scores, and the dependent variables are interview and performance judgments.

Mediating effects on interview judgments. Table 2 presents zero-order correlations between all variables. It shows that the visual cue index is correlated with both the visual

Table 2

Correlations Between Overall Cue Indexes, Personal Reaction Scores, Interview Judgments, and Performance Judgments

\begin{tabular}{|c|c|c|c|c|c|c|}
\hline Variable & 1 & 2 & 3 & 4 & 5 & 6 \\
\hline 1. Visual cue index & - & & & & & \\
\hline 2. Vocal cue index & .26 & - & & & & \\
\hline 3. Visual personal reaction & .59 & .21 & - & & & \\
\hline 4. Vocal personal reaction & .18 & .20 & .46 & - & & \\
\hline 5. Interview judgment & .21 & .32 & .26 & .41 & - & \\
\hline 6. Performance judgment & .14 & .20 & .09 & .26 & .35 & - \\
\hline$M$ & 3.95 & -0.03 & 148.79 & 148.67 & 35.09 & 71.34 \\
\hline$S D$ & 0.96 & 3.30 & 29.59 & 23.74 & 6.91 & 14.14 \\
\hline
\end{tabular}

Note. $N=110$. Correlations greater than .16 are significant at $p<.05$ (one-tailed). 
personal reaction score $(r=.59, p<.05)$ and the interview judgment $(r=.21, p<.05)$, satisfying the first two requirements for mediation effects of visual personal reactions. When interview judgments are regressed against both the visual cue score and the visual personal reaction score, the visual personal score has a significant effect on interview judgments (standardized beta $=.21, p<.05$ ), satisfying the third requirement for establishing mediation (see Table 3). Thus, we conclude that personal reactions such as trust, liking, and attributed credibility at least partially mediate effects of visual cues on interview judgments.

Table 2 also shows that the vocal cue index is significantly correlated with both the vocal personal reaction score $(r=.20, p<.05)$ and interview judgments $(r=.32, p<$ .05 ). When interview judgments are regressed against both the vocal cue score and the vocal personal reaction score (Table 3), the vocal personal reaction score has a significant effect on interview judgments (standardized beta $=.36, p<$ $.05)$. Thus, personal reactions also mediate effects of vocal cues on interview judgments.

Mediating effects on performance judgments. As shown in Table 2, the visual cue score correlates with job performance $(r=.14, p=.07)$. When performance is regressed against both the visual cue index and the visual personal reaction score, the visual personal reaction score has virtually no effect on performance (standardized beta $=.01, n s$ ). These results provide no support for the hypothesis that personal reactions mediate effects of visual cues on job performance (Table 3).

The vocal cue index correlates with job performance $(r=$ $.20, p<.05$ ) and when performance is regressed against both the vocal cue index and the vocal personal reaction score, the vocal personal reaction score has a significant effect on performance (standardized beta $=.23, p<.05$ ). Thus, personal reactions mediate effects of vocal cues on job performance.

Table 3

Mediation Results

\begin{tabular}{lcc}
\hline \multicolumn{1}{c}{ Dependent variable } & Mediator & Independent variable \\
\hline 1. Interview ratings & - & $.21^{*}$ \\
2. Visual cues & $.59^{*}$ & $-\bar{~}$ \\
3. Interview ratings & $.21^{*}$ & .08 \\
1. Interview ratings & - & $.32^{*}$ \\
2. Vocal cues & $.20^{*}$ & $-25^{*}$ \\
3. Interview ratings & $.36^{*}$ & $.20^{*}$ \\
1. Performance ratings & - & -16 \\
2. Vocal cues & $.20^{*}$ & $.23^{*}$ \\
3. Performance ratings &
\end{tabular}

Note. Results are given as standardized beta coefficients. Dependent variables are numbered according to their order in the mediation test. Dashes indicate that data are not applicable at that step.

$* p<.05$.
Relationships between visual and vocal cues. We did not frame hypotheses or research questions about relationships between visual and vocal cues, but correlations presented in Table 2 afford an opportunity to explore these relationships as well. It shows that the visual cue index correlates with the vocal cue index $(r=.26, p<.05)$ and that the visual personal reaction score correlates with the vocal personal reaction score $(r=.46, p<.05)$. These results indicate that people who display attractive visual cues in the interview also tend to display attractive vocal cues and that people who look trustworthy, likable, and credible in the interview also tend to sound trustworthy, likable, and credible.

\section{General Discussion}

Our study shows that both the combined effects of specific visual cues and the combined effects of specific vocal cues explain significant variance in interviewers' judgments about applicants' suitability for employment in managerial positions. Visual and vocal cues also explain significant variance in the favorability of personal reactions that people form about interviewees. Results of tests of mediation effects are consistent with the possibility that effects of visual and vocal cues on interviewers' judgments are mediated by personal reactions, such as liking, trust, and attributed credibility, that interviewers might form about applicants. This finding suggests that interviewers react to applicants' nonverbal visual and vocal cues by developing affective reactions related to the extent to which the applicants, as future employees, might be willing to help them, accept their suggestions, cooperate with them, and so forth. These affective reactions color the interviewers' judgments about applicants' suitability for employment in management positions, perhaps because interviewers assume that if applicants elicit these favorable personal reactions in the interview, they can elicit them on the job as well.

We assumed that people who elicit personal reactions such as those described above from others are more likely to be interpersonally successful. To the extent that such personal reactions make it easier for people to gain the help and cooperation of others, they can also make it easier for people to perform effectively in positions such as management positions that rely heavily on interpersonal success. Consequently, visual and vocal cues that lead interviewers to form favorable personal reactions might also be associated with effective performance in management jobs.

Our results support this argument for vocal cues but not for visual cues. They show that personal reactions that interviewers might form toward applicants on the basis of vocal cues also mediate relations between vocal cues and job performance. This assumes that vocal cues expressed in the interview are reasonably stable and are expressed in similar ways on the job. 
Although our results show that both visual cues and vocal cues can predict job performance, we are unwilling, for several reasons, to recommend that they be explicitly used to make hiring decisions. First, to the best of our knowledge, this is the first study to show any empirical relationship between specific vocal cues in the employment interview and a measure of job performance. This finding is simply too exotic to be translated into practice without extensive replication.

Second, before considering recommendations for practical implementation, these findings must be fully understood. We suggested that nonverbal visual and vocal cues lead to personal reactions that affect interviewers' judgments and effective performance in management positions, and our results are largely consistent with that possibility, but they need to be replicated. In addition, alternative explanations, such as the possibility that interviewers and performance raters fall prey to biasing effects of nonverbal cues that actually have no relationship at all to managerial effectiveness, need to be ruled out.

Third, given the unusual nature of these relationships between nonverbal cues and job performance and the need for replication and full understanding of the effects of nonverbal cues on performance, other predictors that are already relatively well established, understood, and accepted are probably better candidates for practical implementation. We have shown that visual and vocal cues in the interview can be significantly correlated with ratings of job performance, but validity estimates are not very large and there is no evidence that these nonverbal cues can contribute incremental validity to traditional predictors.

In sum, the results of our study show that certain visual and vocal cues displayed in the employment interview can affect interviewers' judgments and predict managerial job performance, perhaps through a mediational mechanism that involves personal reactions that people form toward individuals who display these cues. We believe these results are interesting and important for their implications about how interviewers react to the full range of information generated during selection interviews and how managerial effectiveness might be affected by the expression of such cues. We are reluctant, however, to offer suggestions for practice until much more is known about effects of visual and vocal cues on interpersonal relationships in the employment interview and in the workplace.

\section{References}

Aronovitch, C. D. (1976). The voice of personality: Stereotyped judgments and their relation to voice quality and sex of speaker. The Journal of Social Psychology, 99, 207-220.

Baken, R. (1987). Clinical measurement of speech and voice. London: Taylor \& Francis.

Baron, R. M., \& Kenny, D. A. (1986). The moderator-mediator variable distinction in social psychological research: Concep- tual, strategic, and statistical considerations. Journal of Personality and Social Psychology, 51, 1173-1182.

Boone, D. R. (1977). The voice and voice therapy (2nd ed.). London: Prentice-Hall.

Brown, B. L. (1980). Effects of speech rate on personality attributions and competency evaluations. In H. Giles, W. P. Robinson, \& P. M. Smith (Eds.), Language: Social psychological perspectives (pp. 116-133). Oxford, England: Pergamon Press.

Brown, B. L., Strong, W. J., \& Rencher, A. C. (1973). Perceptions of personality from speech: Effects of manipulations of acoustical parameters. Journal of the Acoustical Society, 54, 29-35.

Buller, D. B., LePoire, B. A., Aune, R. K., \& Eloy, S. V. (1992). Social perceptions as mediators of the effect of speech rate similarity on compliance. Human Communication Research, 19 286-311.

Burnett, J. R. (1993). Utilization and validity of nonverbal cues in the structured interview. Unpublished doctoral dissertation, University of Florida, Gainesville.

Cash, T. F., \& Kilcullen, R. N. (1985). The aye of the beholder: Susceptibility to sexism and beautyism in the evaluation of managerial applicants. Journal of Applied Social Psychology, 15, 591-605.

DeGroot, T. (1997). The impact of managerial nonverbal cues on the reactions of subordinates. Unpublished doctoral dissertation, University of Florida, Gainesville.

Edwards, J. R. (1982). Language attitudes and their implications among English speakers. In R. L. Street \& J. Cappela (Eds.), Sequence and pattern in communicative behaviour (pp. 221244). London: Edward Arnold.

Gifford, R., Ng, C. F., \& Wilkinson, M. (1985). Nonverbal cues in the employment interview: Links between applicant qualities and interviewer judgments. Journal of Applied Psychology, 70, $729-736$.

Greene, M. C. L., \& Mathieson, L. (1989). The voice and its disorders. London: Whurr.

Hollandsworth, J. G., Jr., Kazelskis, R., Stevens, J., \& Dressel, M. E. (1979). Relative contributions of verbal, articulative, and nonverbal communication to employment decisions in the job interview setting. Personnel Psychology, 32, 359-367.

Imada, A. S., \& Hakel, M. D. (1977). Influence of nonverbal communication and rater proximity on impression and decisions in simulated employment interviews. Journal of Applied Psychology, 62, 295-300.

Janz, T. (1982). Initial comparisons of patterned behavior description interviews versus unstructured interviews. Journal of Applied Psychology, 67, 577-580.

Kinicki, A. J., \& Lockwood, C. A. (1985). The interview process: An examination of factors recruiters use in evaluating job applicants. Journal of Vocational Behavior, 26, 117-125.

McGovern, T. V., \& Tinsley, H. E. A. (1978). Interviewer evaluations of interviewee nonverbal behavior. Journal of Vocational Behavior, 13, 163-171.

Mehrabian, A., \& Williams, M. (1969). Nonverbal concomitants of perceived and intended persuasiveness. Journal of Personality and Social Psychology, 13, 37-58.

Motowidlo, S. J., \& Burnett, J. R. (1995). Aural and visual sources of validity in structured employment interviews. Organizational Behavior and Human Decision Processes, 61, 239-249. 
Motowidlo, S. J., Burnett, J. R., Maczynski, J., Witkowski, S., Chelpa, S., \& Wojtachnio, A. (1996). Predicting managerial job performance from personality ratings based on a structured interview: An international replication. Polish Psychological Bulletin, 27, 139-151.

Motowidlo, S. J., Carter, G. W., Dunnette, M. D., Tippins, N., Werner, S., Burnett, J. G., \& Vaughan, M. J. (1992). Studies of the structured behavioral interview. Journal of Applied Psychology, 77, 571-587.

Nighswonger, N. J., \& Martin, C. R., Jr. (1981). On using voice analysis in marketing research. Journal of Marketing Research, 18, 350-355.

Parsons, C. K., \& Liden, R. C. (1984). Interviewer perceptions of applicant qualifications: A multivariate field study of demographic characteristics and nonverbal cues. Journal of Applied Psychology, 69, 557-568.

Pearce, W. B., \& Brommel, B. J. (1972). Vocalic communication in persuasion. The Quarterly Journal of Speech, 58, 298-306.

Raza, S. M., \& Carpenter, B. N. (1987). A model of living decisions in real employment interviews. Joumal of Applied Psychology, 72, 596-603.

Scherer, K. R. (1978). Personality inference from voice quality:
The loud voice of extroversion. European Joumal of Social Psychology, 8, 467-487.

Scherer, K. R. (1979). Personality markers in speech. In K. R. Scherer \& H. Giles (Eds.), Social markers in speech (pp. 5879). Cambridge, England: Cambridge University Press.

Scherer, K. R., London, H., \& Wolf, J. J. (1973). The voice of confidence: Paralinguistic cues and audience evaluation. Journal of Research in Personality, 7, 31-44.

Sharf, D. J., \& Lehman, M. E. (1984). Relationship between the speech characteristics and effectiveness of telephone interviewers. Journal of Phonetics, 12, 219-228.

Wexley, K. N., Fugita, S. S., \& Malone, M. P. (1975). An applicant's nonverbal behavior and student-evaluators' judgments in a structured interview setting. Psychological Reports, 36, 391394.

Young, D. M., \& Beier, E. G. (1977). The role of applicant nonverbal communication in the employment interview. Journal of Employment Counseling, 14, 154-165.

Received December 17, 1997 Revision received January 26, 1999 Accepted January 28, 1999 